\title{
Nexus Between Principals' Leadership Styles and Teachers' Motivation in Secondary School: Case Study South West Shoa Zone, Oromia Regional State, Ethiopia
}

\author{
Getachew Mitiku Kedida \\ Lecturer, Department of Management, Ambo University, Ambo \\ Tesfaye Gedefaw Wolde \\ Lecturer, Department of Economics, Ambo University, Ambo
}

\begin{abstract}
The aim of this paper was examining the relationship between school principal's leadership styles and teacher's motivation using Qualitative and quantitative data collected through multifactor leadership Questionnaire from 193 sample respondents. The data also collected using FGD and analyzing using descriptive, Pearson“s correlation and regression coefficient. The study found that, school principals predominantly exhibited the transactional leadership style. Significant relationships between styles of principal's leadership and teacher's motivation were also found. However, transformational, transactional, and passive/avoidant leadership styles correlated with teacher's motivation at various degrees .there is significant correlations between principals' leadership styles and teacher's intrinsic and extrinsic motivation. Thus, the school principal leadership styles have a potential impact on the teacher's motivation to exert more efforts, and concerned body should concentrate on leadership styles exercised in educational sectors to gain the maximum effort from teachers.
\end{abstract}

Keywords: Leadership Styles, Teachers Motivation, South West Shoa Zone, Ethiopia

DOI: $10.7176 / \mathrm{EJBM} / 11-28-07$

Publication date:October $31^{\text {st }} 2019$

\section{INTRODUCTION}

Education is the process by which an individual acquires many physical and social capabilities demanded by the society in which he or she has been born into (Orobosa, 2010). The purpose of education have been widely accepted, to develop the intellect, to serve social needs, to contribute to the economy, to create an effective workforce, to prepare students for a job or career, to promote a particular social or political system. Education therefore, performs most significant complex social function of the control of tools for societal development. Recognizing the role of education to the individual and society at large, education involved the deliberate efforts on the part of the educator in developing the personality of the child and to prepare him for membership of his society Dienye (2004). Education can create self reliant people over time.

Ethiopian education and Training Policy set aims of producing skilled man power to meet the national socioeconomic development, to bring up citizens who understand, respect and defend the constitution, a citizen who respects democratic values and human rights moreover with good work culture and ethics" (MoE, 1994). Thus, in the realization of these aims, the schools Principals' have a paramount role to play. Supporting this idea, Crum \& Sherman (2008) stated that the principal needed to provide highly valued insights into their daily styles that foster conducive working environment to promote teachers high performance. Principals' should have the basic concept of right leadership styles in leading the school that may affect all followers to carry out duties and responsibilities properly. With this regard, Rue and Byars (2007) pointed out that, leadership is the ability to influence others so that the person is trying to reach the goal enthusiastically. In addition Yukl (2009) described leadership as the deliberate process of a person to emphasize a strong influence on others to guide, create a structure, as well as facilitate activities and relationships within a group or organization. Thus, the Principals' leadership in a group should be able to exert influence, capabilities and activities to influence others around them in order to implement responsibilities as a member of the organization to achieve educational goals. The styles of leadership exhibited by a school principal of a particular school have effects on the teachers' motivation to their work (Ghazala, et al., 2015). However, there are inconsistent empirical evidences with regard to the relationship between Principals' leadership styles and teachers' motivation to their work.

Research indicated that teachers' found to be more committed towards their work when the Principals' intervene and provides encouragement, recognition and set clear goal (Nguni, Sleegers and Denessen, 2006). Other scholars like (Ling \& Ling, 2012; Raman et al., 2015; Dou, et al., 2016) emphasized on the relationship between the Principals' leadership styles and teachers' motivation, and their findings reflected that there is a correlation between Principals' styles of leadership and teachers' motivation to their work. This study was designed to determine what relationship exists between Principals' leadership styles and teachers' motivation in secondary schools of South west shoa zone of Oromia Regional State. 
The general objective of this study was to examine the relationship between school Principals' leadership styles and teachers' motivation in secondary schools of South West Shoa Zone. Specifically:

$\checkmark$ To identify the most predominantly practiced leadership style in the study area

$\checkmark$ To see the relationship between Principals' leadership styles and teachers' motivation.

$\checkmark$ To measure the degree of relationship between different Principals' leadership styles and teachers' motivation.

$\checkmark$ To identify the extent at which leadership styles influences the intrinsic and extrinsic teachers' motivation

$\checkmark$ To examine the relationship between demographic variables and teachers motivation

\section{Material \& Methods}

A comprehensive analysis of the existing literature was conducted in order to obtain the theoretical insights and secondary data. Existing Educational theories, policies, strategies, initiatives, best practices, articles and evaluation reports were commonly used as secondary materials for this study. Questionnaire for the major stockholders primarily teachers' were used as the primary materials to in this research.

\section{Methodology of the Study}

The study followed a mixed research approach. The study used the QUAN-QUAL model. This model was chosen to refine and explain the general pictures of the research problem using both quantitative data and qualitative data (Subedi, 2016), and mainly the study focused on quantitative approach. The qualitative data were used to validate quantitative data and to elaborate quantitative results sufficiently.

This particular design was selected with the assumption that it would sufficiently describe the relationship between school principals' leadership styles (transformational, transactional, and laissez-faire) and teachers' motivation to work under consideration. The required data were collected using survey method, since it is suitable to examine the relationship between the variables under investigation. Selected approaches emphasis on correlational study. Each respondent teacher were reflected their view by responding to the MLQ items and teachers motivational factor items to report on the leadership styles and its influence on teachers' motivation. The data was analyzed using descriptive statistics. Using SPSS descriptive statistics such as frequencies, percentage, mean, standard deviation, and Pearson correlation, and regression analysis coefficient were used to describe the relationship between variables under consideration. Qualitative data obtained from focused group discussion, was analyzed and used for triangulation purpose.

\section{Sampling Technique and Sample Size}

The study conducted at south west shoa zone, and concludes about the target population of the study area. The study used a mix of random and purposive sampling approach. First, the study select six woreda purposively due to the existence of sever problems related with school principal leadership styles. Second, one secondary school selected randomly from each woreda. Thirdly, 193 secondary school teachers were selected as the main respondent in this study.

Therefore, to make the sample more representatives the sample size of the study was determined using the formula formed by Yamane (1973) to identify appropriate total sample size. This formula was used because it is one of the formulas in determining the sample size in probability sampling technique. The formula is reliable to $95 \%$ and less than $5 \%$ deviation factor. Thus the sample size was computed as: $n=\frac{N}{\left(1+N e^{2}\right)}=\frac{372}{\left(1+372 e^{2}\right)}=193$

\section{Method of data collection and analysis}

The required data were collected using structured questionnaire and also using focus group discussions (FGD. The data was analyzed using descriptive statistics. Statistical Product for Social Science (SPSS) previously called as Statistical Package for Social Sciences (SPSS) was used to analyze the data. Descriptive statistics such as frequencies, percentage, mean, standard deviation, and Pearson correlation, and regression analysis coefficient model were used to describe the relation between variables under consideration.

\section{Results and discussions}

\section{General characteristics of the Respondents}

This chapter deals with the presentation, analysis and interpretation of data collected from respondents through questionnaire and group focused discussion. The study includes a sample of 193 secondary school teachers. 175 $(91.15 \%)$ of the questionnaire that was distributed to teachers was returned, and only $18(9.33 \%)$ were failed to return. Accordingly, the largest sample respondent's lays under age category between 26-30 years old. In terms of marital status, majority of the teachers participated in the survey are married (77.1\%). Considering the respondents qualification, majority of respondents are BA/Bsc. The result indicated that, the majority of teachers were served for more than ten years and that shows most of the teachers are experienced in teaching and school environment. Almost, all the teachers had their first degree and that shows secondary school teachers working in 
South West Shoa Zone were fulfilled the principles of the Federal Democratic Republic of Ethiopia, Ministry of Education requirement for the secondary schools.

Table 1: Unit Analysis of comparison of Leadership Styles in Practice

\begin{tabular}{|c|c|c|c|c|}
\hline \multirow[b]{2}{*}{ Schools } & \multirow[b]{2}{*}{ Scores } & \multicolumn{3}{|c|}{ Styles of Leadership } \\
\hline & & Transformational & Transactional & Laissez Faire \\
\hline \multirow{3}{*}{ Geresu Diki (1) } & $\mathrm{N}$ & 38 & 38 & 38 \\
\hline & Mean & 3.44 & 2.44 & 2.15 \\
\hline & St. deviation & .582 & .516 & .630 \\
\hline \multirow{3}{*}{ Woliso (2) } & $\mathrm{N}$ & 25 & 25 & 25 \\
\hline & Mean & 3.75 & 3.54 & 2.26 \\
\hline & St. deviation & .757 & 1.264 & .797 \\
\hline \multirow{3}{*}{ Dilela(3) } & $\mathrm{N}$ & 20 & 20 & 20 \\
\hline & Mean & 2.12 & 3.11 & 2.10 \\
\hline & St. deviation & .536 & .511 & .465 \\
\hline \multirow{3}{*}{ Hibret Fire (4) } & $\mathrm{N}$ & 22 & 22 & 22 \\
\hline & Mean & 3.2 & 2.19 & 2.54 \\
\hline & St. deviation & .436 & .566 & .650 \\
\hline \multirow{3}{*}{ Goro (5) } & $\mathrm{N}$ & 19 & 19 & 19 \\
\hline & Mean & 3.35 & 2.24 & 2.17 \\
\hline & St. deviation & .555 & .548 & .608 \\
\hline \multirow{3}{*}{ Chitu (6) } & $\mathrm{N}$ & 16 & 16 & 16 \\
\hline & Mean & 2.87 & 3.56 & 2.51 \\
\hline & St. deviation & .542 & .536 & .489 \\
\hline \multirow{3}{*}{ Teji (7) } & $\mathrm{N}$ & 17 & 17 & 17 \\
\hline & Mean & 2.33 & 3.56 & 2.01 \\
\hline & St. deviation & .482 & .512 & .684 \\
\hline \multirow{3}{*}{ Dawo (8) } & $\mathrm{N}$ & 18 & 18 & 18 \\
\hline & Mean & 2.34 & 3.23 & 2.12 \\
\hline & St. deviation & .656 & .546 & .487 \\
\hline
\end{tabular}

Source: Primary Survey Data, 2018

As indicated in the above table, principals of schools under investigation employed different types of leadership styles in different level. The statistical mean values for school $1(M=3.44, S D=0.582)$, school $2(M$ $=3.75, S D=1.264)$, school $4(M=2.44, S D=0.436)$ and school $5(M=2.15, S D=0.555)$ indicated that principals of the three schools dominantly employed the transformational leadership style of leadership. On the other hand, mean values for school $3(M=2.65, S D=0.511)$, school $6(M=2.26$, $S D=.536)$, school $7(M=3.56$, $S D=.512)$ and school $8(M=3.23, \mathrm{SD}=.546)$ indicated that principals of the five schools dominantly employed the transactional styles of leadership style. Therefore, the majority of the school principals dominantly employed the transactional type of leadership styles followed by the transformational leadership whereas laissez-faire is the least practiced style of leadership in all the schools. The summarized table below also agrees with the above unit analysis.

Table 2: Summarized Comparison of Leadership Styles in Practice

\begin{tabular}{|l|c|c|c|}
\hline Mean Score of Variables & Number & Mean & Std. Deviation \\
\hline Variables/Leadership Styles & 175 & 3.3247 & .67132 \\
\hline Transactional Leadership & 175 & 2.5437 & .43055 \\
\hline Transformational Leadership & 175 & 2.1352 & .3285 \\
\hline Laissez-Faire Leadership & & & \\
\hline
\end{tabular}

Source: Primary Survey Data, 2018

The results in table 2 above show that, the mean values for all of the research variables are above the mid value which is 3.0. Accordingly, the statistical result is depicting that respondents observed school principals have practiced transactional leadership style $(\mathrm{M}=3.32, \mathrm{SD}=0.67)$. On the other hand, laissez-faire leadership style (M $=2.13, \mathrm{SD}=0.33)$ is the least practiced leadership style as compared to the transactional and transformational leadership style $(\mathrm{M}=2.54, \mathrm{SD}=0.43)$. Therefore, according to the result, school principals dominantly practiced the transactional type of leadership style followed by the transformational leadership whereas laissez-faire is the least practiced style of leadership. 
Table 3: The Regression Analysis Result of Leadership Styles and Motivation

\begin{tabular}{|c|c|c|c|c|c|c|}
\hline \multirow{2}{*}{\multicolumn{2}{|c|}{ Model }} & \multicolumn{2}{|c|}{$\begin{array}{l}\text { Unstandardized } \\
\text { Coefficients }\end{array}$} & \multirow{3}{*}{$\begin{array}{l}\text { Standardized } \\
\text { Coefficients } \\
\text { Beta }\end{array}$} & \multirow[t]{2}{*}{$\mathrm{t}$} & \multirow[t]{2}{*}{ Sig. } \\
\hline & & $\mathrm{B}$ & Std. Error & & & \\
\hline \multirow[t]{4}{*}{1} & (Constant) & .338 & .261 & & 1.297 & .196 \\
\hline & $\begin{array}{l}\text { Transformational } \\
\text { Leadership }\end{array}$ & .746 & .096 & .634 & 7.769 & .000 \\
\hline & Transactional Leadership & -.057 & .080 & -.058 & -.714 & .476 \\
\hline & Passive/Avoidant & .175 & .071 & .156 & 2.477 & .064 \\
\hline
\end{tabular}

Dependent Variable: Motivation: Source: Primary Survey Data, 2018

Given the regression results, for transformational leadership style the calculated t value (7.769) is larger than the critical $t$ value (3.182) which is statistically significant. The beta coefficient of 0.634 indicates that there is a statistically significant linear and positive correlation between principals' transformational leadership style and teachers' motivation. It means that, whenever the principal employed the transformational leadership style there was bound to be a direct response in relation to teachers' motivation which was either low or high amongst the teachers. This finding supports Base \&Avolio (2000) study which found that transformational leadership style involves the creation of an emotional attachment between leaders and employees. Thus, transformational leadership motivates the follower to greater levels by moving beyond the exchange level.

The beta coefficient value of -0.058 in table 4 above revealed that there is a linear and negative association between transactional leadership and teachers motivation, even if it not statistically significant. The result of the finding agrees with Niguni et al (2006) findings that indicated transactional leadership motivates through simple rewards such as exchanging work for financial compensation. Followers received a reward only when they had completed a task.

Passive/Avoidant leadership style was also another variable used to analyze its relationship and influence on motivation. In line with this, the beta coefficient value of 0.156 indicates that there is a statistically significant and positive correlation between principals' passive/avoidant leadership style and teachers' motivation.

Thus, the findings revealed that transformational leadership style motivates teacher's more than transactional leadership. In general we can conclude that, better use of transformational leadership would lead to higher teacher's motivation.

Table 4: The Correlation Analysis Result of leadership Styles, and Intrinsic and Extrinsic Motivation Variables

\begin{tabular}{|c|l|l|l|}
\hline \multirow{5}{*}{ Transformational leadership } & Pearson Correlation & $.572 * *$ & Extrinsic Motivation \\
& Sig. (2-tailed) & .000 & $.612^{* *}$ \\
& $\mathrm{~N}$ & 175 & .000 \\
\hline \multirow{2}{*}{ Transactional Leadership } & Pearson Correlation & $.404 * *$ & 175 \\
& Sig. (2-tailed) & .000 & $.419^{* *}$ \\
& $\mathrm{~N}$ & 175 & .000 \\
\hline \multirow{2}{*}{ Passive/Avoidant Leadership } & Pearson Correlation & $.307 * *$ & 175 \\
& Sig. (2-tailed) & .000 & $.400^{* *}$ \\
& $\mathrm{~N}$ & 175 & .000 \\
\hline
\end{tabular}

\section{**. Correlation is significant at the 0.01 level (2-tailed). Source: Primary Survey Data, 2018}

Dependent Variable: Intrinsic and Extrinsic Motivation

The paper found out there is significant relationship between the teachers Motivation Sources (intrinsic and extrinsic), and principals leadership styles (transformational transactional, passive/avoidant). The Pearson (2-tailed) correlations analysis shows a statistically significant correlation between principals transformational leadership styles and teachers intrinsic motivation $(r=0.572, p<0.001)$. Principals transactional leadership style also have a significant relationship with teachers intrinsic motivation $(\mathrm{r}=0.404, \mathrm{p}<0.001)$. In the same manner, passive/avoidant also indicated the existence of significant correlation with teacher's intrinsic motivation $(r=$ $0.307, \mathrm{p}<0.001)$. Thus, it can be concluded that, the results of the finding The finding supports the ideas of Base \& Avolio (2003) with respect to transformational leadership that stated transformational leadership style involves the creation of an emotional attachment between leaders and employees. It motivates subordinates and appeal to their ideals and moral value by creating and representing an inspiring of the future. 
Table 5: Correlation Analysis result of Effect Size of Leadership styles on Motivation

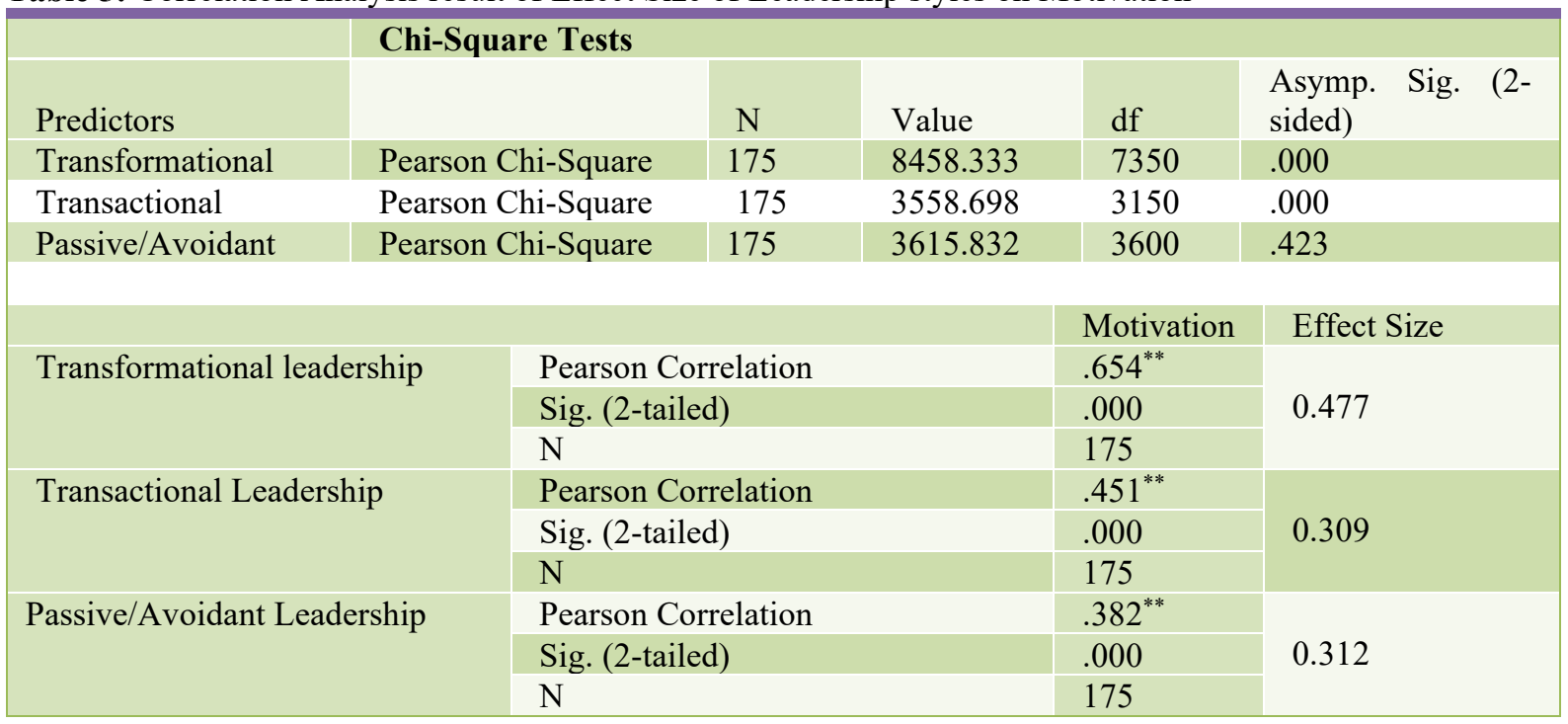

**. Correlation is significant at the 0.01 level (2-tailed): Source: Primary Survey Data, 2018

As stated in the above table, the findings indicated that the effect size value of 0.477 indicated that transformational leadership style has a greater impact on teacher's motivation compared to transactional leadership style (0.309) and passive/avoidant leadership (0.312). The findings are consistent with previous studies by Burns (1978) emphasized on the motivational role in the human resource leadership, and leaders who exhibit transformational leadership styles are more effective in achieving significantly higher commitment levels than transactional, and passive/ avoidant leadership styles. Thus transformational leadership is the important motivators that have played a significant role in teacher's motivation than the transactional and passive/avoidant leadership style. With respect to the degree of the influence of independent variables, transformational leadership moderately related to motivation $(0.477)$ since, the effect size is greater than 0.3 (modest) and approached to 0.5 (moderate). Whereas, the relationship between transactional (0.309) and passive/avoidant (0.312) leadership styles with motivation was modest.

\section{Comparison of Leadership Styles in Practice}

One of the questions to be answered in this study was to identify which type of leadership style is dominantly practiced in secondary schools. Therefore, the focused group discussion participants were asked to reflect their view and observation on the kind of principal's leadership style (transformational, transactional, and Laissez-Faire) dominantly practiced in their respective school. And the information obtained confirmed that the majority of school principals were practicing transactional model of leadership style. Therefore, the data obtained from the qualitative approach were not deviated from the quantitative result. But the participants added the idea that was not basically included in the quantitative part of the investigation, that is, they pointed out that, the school principals has no complete right and authority to exercise the style he or she want to practice because of the interventions of different officials mostly political leaders from woreda and town administration. They underlined, this is one of the most challenging factor confusing and making the principals to lose confidence in following and exercising specific philosophy of leadership style in leading their school.

Three hypotheses were tested in this study to examine the relationship between principals leadership styles and teachers motivation.

$\checkmark \quad$ There is no significant and positive relationship between transformational leadership styles and teachers motivation.

$\checkmark$ There is no significant relationship between transactional leadership style and teachers motivation

$\checkmark$ There is no significant relationship between passive/avoidant leadership style and teachers motivation

Based on the above assumptions focused group discussion participants were asked to reflect their view, opinion, and their practical observation in their respective school. The result of the information obtained from the participants of focused group discussion, of five sample secondary schools reflected that, teachers who are worked under principals who practiced transformational leadership styles are highly motivated and showing they became self regulated teachers. This confirmed the result of the quantitative analysis. Whereas, teachers from three sample secondary schools indicated that teachers worked under principals who practiced transactional leadership styles are more motivated. According to their view the economic impact highly influences the teacher's motivation than the impact of inspirational motivation which is the feature of transformational leadership. Therefore, the result of the information obtained from teachers of the three sample schools was deviated from result of the quantitative 
analysis. This may indicate that, the approaches that teachers experienced to be motivated varies from school to school provided that they are operating within the same system.

\section{Conclusion}

The findings of this research showed significant predictive relationship between principals leadership styles and teachers motivation. The regression equation demonstrating the relationship between leadership styles and teachers motivation is found as significant. Thus, school principal leadership styles have a potential impact on the teacher's motivation to work. However, many dynamic factors like school climate and school cultures influence teacher's motivation. The research contained in the literature review part of this study represented the work that has been conducted in relation to motivation and principal leadership behaviors have been shown to effect the overall school work environment and teacher's motivation. Teachers need to perceive principal behaviors as motivational in order to increase their level of motivation under their current principal. However, in order to create such situation knowledge of leadership styles, motivational theories allowed the principal to align behaviors that are more motivating to teachers. Therefore, the knowledge of the principals to select the right leadership style will have a significant influence on improving and enhancing teacher's motivation to work.

\section{Recommendation}

Based on the research finding the researcher makes the following recommendations as necessary to improve teachers' motivation in relation to principals' leadership style in secondary schools:

$\rightarrow$ As the study indicates, for principals to succeed in today's fast changing work environment, it is recommended that they need to adopt a transformational leadership style rather than transactional or laissez-faire styles to enhance teachers motivation consistently and efficiently; which will in turn generate higher teachers motivation to work.

The concerned authorities such as Ministry of education, Regional Education Bureaus, Zonal, and Wereda Education Offices need to work consistently and effectively on the implementation of principalship standardization. Moreover, school principals must be equipped with the knowledge of educational leadership that helps them to select appropriate leadership style, execute their leadership responsibilities, and generally to align their leadership behavior towards factors that are motivating teachers to work.

$\checkmark$ Now and perhaps more than ever, schools have a need of good leadership and motivational methods. Promoting teachers on the merit of well payment, increase teachers 'remuneration, review teachers pay in relation to the teachers work and standards of living as a motivational strategy to ensure the achievement of school goals. These kinds of motivational strategy have a significant effect in responding to the extrinsic teacher's motivational needs. Thus, the ministry of education should establish functional system that supports the implementation of such motivational strategies.

$\rightarrow$ The finding indicated that transformational leadership had strong and positive correlations with teacher's motivation. Therefore, school principals should be aware of the importance of transformational leadership style and try to display it in their daily practices.

\section{REFERENCES}

Bass, B., \& Avolio, B. (2004). MLQ Multifactor Leadership Questionnaire sample set: Technical report, leaders form, rater form, and scoring key for MLQ from 5x-Short (2nd ed.). Redwood City, CA: Mind Garden

Bass, B., Avolio, B., Jung, D., \& Berson, Y. (2003). Predicting Unit Performance by Assessing Transformational and Transactional Leadership. Journal of Applied Psychology, 88, 207-218.

Retrieved October 9, 2017 from ttp://forum.hrdiscussion.com/forum5/topic579.html

Dienye U. (2004) Sociology for Education Students: Amethyst and Colleagues, PortHarcourt.

Dou, D., Devos, G., \& Valcke, M. (2016). The relationships between school autonomy gap, principal leadership, teachers" job satisfaction and organizational commitment. Educational Management Administration and Leadership.

Ghazala, N., Riffat-un-Nisa, A., \& Anam, N. (2015). Relationship between Leadership Styles of School Heads and their teachers" Job Satisfaction as Moderated by Locus of Control and Task Structure. Journal of Educational Research, 18(2), 14-31

Ling, S., \& Ling, M.(2012). The Influence of Transformational Leadership on Teacher Commitment towards Organization, Teaching Profession, and Student Learning in Secondary Schools in Miri, Sarawak, Malaysia. International Journal for Educational Studies, 4(2)

Nguni, S., Sleegers, P., \& Denessen, E. (2006). Transformational and transactional leadership effects on teachers" job satisfaction, organizational commitment, and organizational citizenship behavior in primary schools: The Tanzanian case. School Effectiveness \& School Improvement, 17(2), 145-177. Retrieved Oct, 12, 2017, from Academic Search Premier database

Orobosa U. (2010) Education and National Development in Nigeria: Vanguard Newspaper January 20, 2010 
Raman, A., Mey, C. H., Don, Y., Daudi, Y., \& Khalid, R. (2015). Relationship between Principals" Transformational Leadership Style and Secondary School teachers" Commitment. Asian Social Science.

Subedi, D. (2016). Explanatory sequential mixed method design as the third research community of knowledge claim. American Journal of Educational Research, 4 (7), 570-577

Yamane T. (1973). Statistics: An Introductory Analysis, 2nded, New York

Yukl, G. 2006. Leadership in Organizations. Prentice Hall.

Yukl, G., (2009) Leading organizational learning: Reflections on theory and research. The Leadership Quarterly, no. 20 , vol, $1,49-53$ 